www.jmscr.igmpublication.org

Impact Factor (SJIF): 6.379

Index Copernicus Value: 71.58

ISSN (e)-2347-176x ISSN (p) 2455-0450

crossrefDOI: https://dx.doi.org/10.18535/jmscr/v6i7.167

Journal Of Medical Science And Clinical Research

\title{
Comparison of Ondansetron with Dexamethasone in the Prevention of Post Operative Nausea and Vomiting in ENT Surgeries
}

\author{
Authors \\ Dr Sandhya M S ${ }^{1}$, Dr Sugandha K $\mathbf{R}^{2}$ \\ ${ }^{1}$ Asst. Professor, Dept. of Anesthesiology, Government Medical College, Thirvananthapuram, Kerala \\ ${ }^{2}$ Associate Professor, Dept. of Anesthesiology, Government Medical College, Thirvananthapuram, Kerala \\ Corresponding Author \\ Dr Sugandha K R \\ Associate Professor, Dept. of Anesthesiology, Govt Medical College, Thirvananthapuram, Kerala, India
}

\begin{abstract}
Back ground: Post-operative nausea and vomiting is a common morbidity observed after anesthesia and surgery. It is of significance especially in the context of day care surgery. PONV is the reason for unanticipated hospital admission, resulting in stress and financial burden. In this prospective double blind study, we have compared the effectiveness of Dexamethasone and Ondansetron in the prevention of PONV.

Materials and Methods: After obtaining approval of the hospital ethical committee and informed consent, 60 adult patients of either sex, scheduled for elective ENT surgeries under general anaesthesia were included in the study. In this prospective double blind study, Group A received Ondansetron $4 m g$ and Group B received Dexamethasone $8 m g$ just before induction of general anesthesia. The antiemetic efficacy and side effects were analyzed. The results of the study were statistically analyzed using the student $t$ test and chi square test.

Results: All episodes of nausea and vomiting in the first 24 hour postoperative period during the interval of 0-6 hrs (early PONV) and 6-12 hours (late PONV) were evaluated by a numeric scoring system of $P O N V$. The entire post operative experience was assessed using an 11 point verbal numeric scoring system $(0=$ not at all satisfied, $10=$ fully satisfied $)$.There is no statistically significant difference between Ondansetron and Dexamethasone in preventing postoperative nausea and vomiting either in the early or late postoperative period. But clinically significant difference was noted between these two groups .ie, when $83.3 \%$ had no nausea and vomiting in the Dexamethasone group $93.3 \%$ had no nausea and vomiting in Ondansetron group. But in the late postoperative period, Dexamethasone had a better effect, ie, while $86.7 \%$ had no vomiting in Ondansetron group, $93.3 \%$ were free of vomiting episodes in Dexamethasone group. Patient satisfaction score was also comparable.

Conclusion: In the prevention of postoperative nausea and vomiting, Ondansetron is clinically better than Dexamethasone in early postoperative period. Dexamethasone is more effective in late postoperative period. Dexamethasone being cheaper and easily available can be considered in prevention of PONV.

Keywords: PONV, Ondansetron, Dexamethasone.
\end{abstract}




\section{Introduction}

Postoperative Nausea and Vomiting (PONV) is a relatively common complication that results in patient discomfort and prolonged stay in post anaesthesia care Unit. It can also be life threatening if it predisposes to pulmonary aspiration syndrome. ${ }^{1,6}$ the wide spread use of opioids for postoperative pain relief is acting as a double-edged sword aggravating nausea and vomiting. The act of vomiting produces more pain and thus a vicious cycle ensues. In the setting of Day Care Surgery, PONV can cause debilitation, limitation of physical activity and loss of wages.

PONV is multifactorial and hence no single drug is effective in allcases.In addition to conventional drugs like Metoclopramide, Droperidol and Prochlorperazine, newer drug like Ondansetron, 2,3 the 5HT3 antagonist which has proved its benefit in cancer chemotherapy ${ }^{4}$ has now been extended to the management of PONV. The use of Dexamethasone was also first demonstrated in cancer chemotherapy where it was found to be better than the usual antiemetics and also potentiating their actions. Dexamethasone is cheap and administration of a single dose is not associated with significant side effects like adrenocortical suppression, hypoglycemia or wound infection. ${ }^{5}$

The present study was conducted to evaluate the effect of Dexamethasone as an agent to prevent PONV in comparison to Ondansetron.

\section{Materials and Methods}

In our study, we included 60 adult patients of ASA 1 and 2 between 18 and 60 years of age, of either sex, scheduled for elective ENT surgeries under general anaesthesia. Approval of the hospital ethical committee and written informed consent were obtained. Patients with history of gastro - oesophageal reflux, body weight $>75 \mathrm{~kg}$., history of motion sickness or prior history of PONV, who are menstruating or breast feeding, who had taken drugs with antiemetic effects (Phenothiazines, Benzamides, Scopolamine, Corticosteroids, and Tricyclic anti depressants) within 24 hours before surgery, were excluded from the study.

The patients were made to fast for 8 hours prior to surgery. All were given Tab Ranitidine 150mg on the previous night and on the morning of surgery and Diazepam 5mg orally at 6 a.m. on the day of surgery. Patients were allocated randomly to one of the 2 groups by a computer generated randomization scheme to receive the following drugs by I/V route. Group A Ondansetron $4 \mathrm{mg}$ in $0.9 \%$ saline, total $5 \mathrm{~m} 1$. Group B - Dexamethasone $8 \mathrm{mg}$ in $0.9 \%$ saline, total $5 \mathrm{~m} 1$. It was prepared by personnel not involved in the study in identical $5 \mathrm{~m} 1$ syringes to ensure blinding to the anaesthestist. Medications were administered intravenously before inductions of anaesthesia. All patients were given general anesthesia with endotracheal intubation. Fentanyl $1 \mathrm{mcg} / \mathrm{kg}$ was given $\mathrm{I} / \mathrm{V}$ prior to induction to provide background analgesia. Induction was with Thiopentone sodium 5mg/kg. Sympathetic response to laryngoscopy and intubation were attenuated by prior administration of preservative free $2 \%$ lignocaine $1.5 \mathrm{mg} / \mathrm{kg}$. Intubation was facilitated by succinylcholine $2 \mathrm{mg} / \mathrm{kg}$. Pulse rate, $\mathrm{ECG}, \mathrm{BP}, \mathrm{SpO}_{2}$ were monitored. Maintenance of anaesthesia was with $\mathrm{N}_{2}$ Oand intermediate acting muscle relaxant Vecuronium. Analgesia was supplemented with injection Diclofenac sodium $75 \mathrm{mg}$ IM. At the end of procedure, the secretions and blood in oropharynx were suctioned under vision .Residual neuromuscular blockade was antagonized with $0.05 \mathrm{mg} / \mathrm{kg}$ Neostigmine and $0.01 \mathrm{mg} / \mathrm{kg}$ Glycopyrrolate and extubation was done when patient was awake. After shifting to recovery room, patients were. observed for 24 hours and vital signs, nausea and vomiting and pain assessment were done. All episodes of nausea and vomiting during the interval of 0-6 hrs (early PONV) and 6-24 hours (late PONV) were evaluated by a numeric scoring system of PONV.

$0=$ no nausea or vomiting

$1=$ nausea but no vomiting

$2=$ vomiting once in 30 minutes or more 
$3=$ persistent nausea ( $>30$ minutes) or 2 or more vomiting in 30 minutes

Any patient having a PONV score of 2 was treated with Metoclopramide $10 \mathrm{mg}$ as a rescue antiemetic. A PONV score of 3 was taken as severe vomiting. The side effects of each drug were also noted. Finally, at the end of 24 hours after surgery, the patients were asked to give an assessment of their satisfaction regarding PONV using a 11 point verbal numeric scoring system (0 $=$ not at all satisfied, $10=$ fully satisfied).The results of the study were statistically analysed using the student $t$ test and Chi square test and the results were compared. $\mathrm{p}$ value $<0.05$ is considered significant. The observations are represented both numerically and graphically.

\section{Observation \& Analysis}

The demographic profile which include age, weight and sex were comparable and no significant differences [p>0.05] were observed between the two groups.

\begin{tabular}{|l|c|c|c|}
\hline Para meters & $\begin{array}{c}\text { Group } \\
\text { A }\end{array}$ & $\begin{array}{c}\text { Group } \\
\text { B }\end{array}$ & P Value \\
\hline Age (year) & $30.23 \pm 10.81$ & $33.40 \pm 14.28$ & 034 \\
\hline Weight Kg & $50.07 \pm 7.5$ & $48.53 \pm 6.3$ & 1 \\
\hline $\begin{array}{l}\text { Sex } \\
\text { Male/Female }\end{array}$ & $16 / 14$ & $15 / 15$ & 0.796 \\
\hline
\end{tabular}

On studying PONV during the early postoperative period , ie; $1^{\text {st }} 6 \mathrm{hrs}$, there was no significant difference between the two drugs.83.3\% had no vomiting in the dexamethasone group as compared to $93.3 \%$ in the ondansetron group $(\mathrm{p}>0.05)$.

Table 2: Comparison of PONV (0-6) under different drug

\begin{tabular}{|l|c|c|c|c|c|c|}
\hline \multirow{2}{*}{ Nausea } & \multicolumn{2}{|c|}{ Ond } & \multicolumn{2}{c|}{ Dex } & \multirow{2}{*}{$\mathrm{P}$} \\
\cline { 2 - 5 } & Count & Percent & Count & Percent & & \\
\hline No vomiting & 28 & 93.3 & 25 & 83.3 & 1.21 & \multirow{2}{*}{0.23} \\
\hline Presence of vomiting & 2 & 6.7 & 5 & 16.7 & & \\
\hline
\end{tabular}

Similarly two groups were comparable when assessed for complete response in the delayed vomiting in Ondansetron group as compared to postoperative period(6-24hrs).86.7\% had no $93.3 \%$ in dexamethasone group. $(\mathrm{p}=0.39)$.(Table 3$)$

Table 3: Comparison of PONV (6-24 hrs) under different drug

\begin{tabular}{|l|c|c|c|c|c|c|}
\hline \multirow{2}{*}{ Nausea } & \multicolumn{2}{|c|}{ Ond } & \multicolumn{2}{c|}{ Dex } & Z & \multirow{2}{*}{ P } \\
\cline { 2 - 5 } & Count & Percent & Count & Percent & & \\
\hline No vomiting & 26 & 86.7 & 28 & 93.3 & \multirow{2}{*}{0.86} & 0.39 \\
\hline Presence of vomiting & 4 & 13.3 & 2 & 6.7 & & \\
\hline
\end{tabular}

$13.3 \%$ of patients in ondansetron group required rescue antiemetics. This was comparable when analysed statistically. When comparing the side effects, $10 \%$ of patients of Ondansetron group and $3.3 \%$ of patients in dexamethasone group had headache. Transient perineal itching probably due to the vehicle was experienced in $36.7 \%$ of patients in dexamethasone group. Other side effects were not significant. (Figure 4).
Table 5: Patient satisfaction level in Ondansetron and Dexamethasone groups do not differ statistically $(\mathrm{p}=0.7)$.

\begin{tabular}{|l|c|c|c|c|c|}
\hline Drug & Mean & SD & $\mathrm{N}$ & $\mathrm{T}$ & $\mathrm{P}$ \\
\hline Ond & 5.87 & 0.94 & 30 & 0.39 & 0.70 \\
\cline { 1 - 4 } Dex & 5.97 & 1.07 & 30 & & \\
\hline
\end{tabular}




\section{Distribution of the sample patients according to side effect}

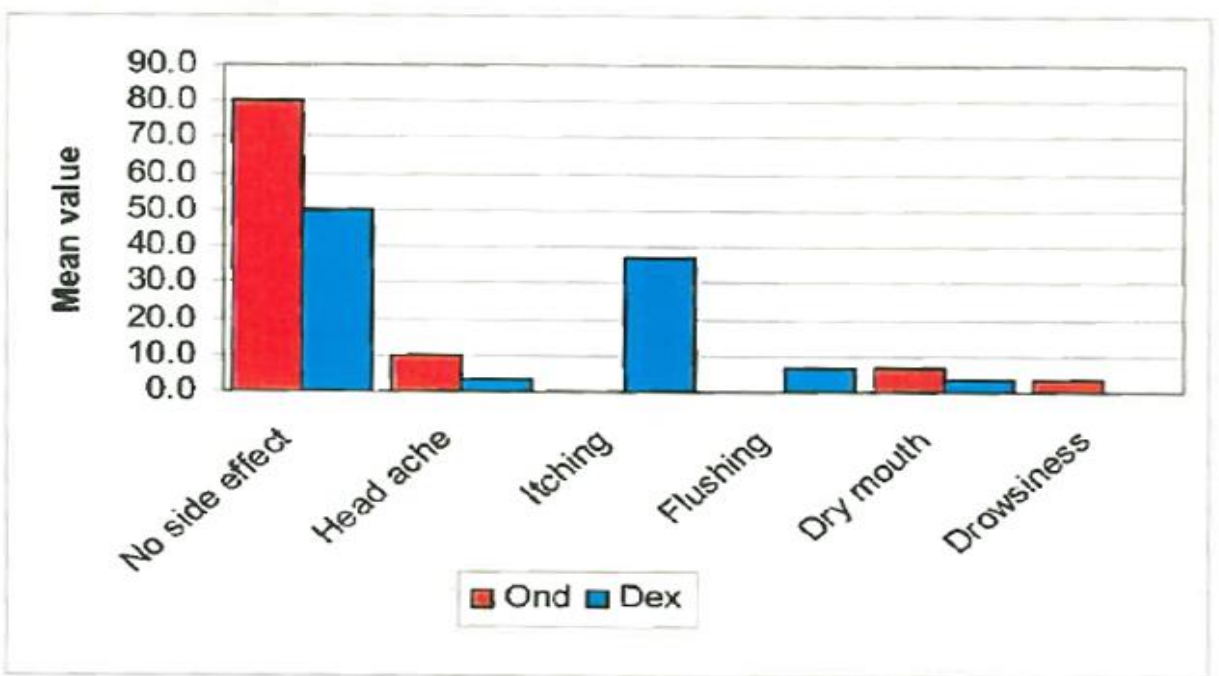

\section{Discussion}

There is a high incidence of PONV in ENT surgeries. ${ }^{7}$ this study was done to compare the effectiveness of intravenous Ondansetron 4mg and Dexamethasone $8 \mathrm{mg}$, in the prevention of PONV in ENT surgeries. The results show that in the early postoperative period of 0-6 hrs, Ondansetron was superior to Dexamethasone in preventing severe emetic episodes requiring rescue antiemetics. Dexamethasone has a lag period of action of action of two hours. ${ }^{11}$ In the present study, Dexamethasone was given at the time of induction, and the average duration of surgery was one hour. That may be reason for increased incidence of PONV in Dexamethasone group.

In the late postoperative period (6-24 hrs), the two groups were comparable in their efficacy to produce complete response and the need to avoid rescue antiemetics. Dexamethasone had less incidence of PONV during the late postoperative period, though the effect was not statistically significant. In another study, Thomas $\mathrm{R}$ and Jones $^{8}$ studied the effect of $8 \mathrm{mg}$ Dexamethasone alone and in combination with Ondansetron $4 \mathrm{mg}$ in the prophylaxis of PONV in 177 patients undergoing day care gynaecological surgery. In their double blinded, prospective, randomised controlled study, they found that failure of prophylaxis during the first three hours after surgery was recorded as $22 \%, 28.3 \%$ and $8.6 \%$ of patients who had received Ondansetron,
Dexamethasone, and combination respectively. The incidences during the next 9 hours were $30.5 \%, 35 \%$ and $24.1 \%$, respectively. During the late period (12 to 24 hours) Dexamethasone showed only slight decrease (13.5\%) when compared to the effect of other groups (15\% and $15.5 \%)$. The overall incidence, 24 hours post surgery, were $42.4 \%, 48.3 \%$ and $34.5 \%$. The effect of Ondansetron and Dexamethasone were comparable both during the immediate and late post operative periods, but the combination was found superior to the individual drugs used alone. B. Subramaniam et $\mathrm{al}^{9}$ studied the antiemetic efficacy, cost effectiveness and clinical utility of prophylactic Ondansetron and Dexamethasone compared with placebo in prevention of PONV in 135 children between 2 and 15 years undergoing strabismus surgery. They found that the incidence of PONV was significantly greater in the placebo group than in the Ondansetron and Dexamethasone group and that the incidence in the Dexamethasone $(24.4 \%)$ and Ondansetron (33.3\%) were comparable .The incidence of early PONV (0 to 6 hours) was comparable in the Ondansetron group (17.8\%) and Dexamethasone (24.4\%) group. The incidence of PONV in the late postoperative period (6 to 24 hours) was significantly lower in the Dexamethasone group $6.67 \%$ than in the Ondansetron $(24.4 \%)$ and placebo group (31.1\%). Recovery time, fast tracking time and parental satisfaction scores were 
comparable in the Ondansetron and Dexamethasone groups. They assessed that the cost benefit with Dexamethasone was approximately 22 times less than that of Ondansetron. Another study by Wang et $\mathrm{al}^{10}$ was on the efficacy of different doses $(10 \mathrm{mg}, 5 \mathrm{mg} \&$ $2.5 \mathrm{mg}$ ) of Dexamethasone given IV for prevention of PONV associated with epidural morphine for post caesarean analgesia. In their placebo controlled study which included 180 parturients, they found that $10 \mathrm{mg} \& 5 \mathrm{mg}$ Dexamethasone were more effective than saline in preventing PONV. The difference between 10mg \& 5mg Dexamethasone were not statistically significant. Dexamethasone $2.5 \mathrm{mg}$ was partially effective. They concluded that Dexamethasone 5 $\mathrm{mg}$ IV may be the minimum effective dose for this purpose. Khosrou et al ${ }^{12}$ compared the effect of single bolus administration of metoclopramide $150 \mathrm{mcg} / \mathrm{kg}$, Dexamethasone $150 \mathrm{mcg} / \mathrm{kg}$ and their combination on reduction of PONV after strabismus surgery under general anaesthesia. Their study group included 132 patients, 2 - 14 years of age. The incidence of PONV in the combination was significantly lower than either of the drugs when given alone. Dexamethasone group was associated with fewer side effects when compared to that of metoclopramide. Margarita Coloma et $\mathrm{al}^{13}$ studied the effect of routine use of Dexamethasone in facilitating early recovery process after anorectal surgery. Out patients undergoing anorectal surgery with standardized monitored anaesthesia care technique were randomly assigned to receive either Dexamethasone $4 \mathrm{mg}$ IV or an equal volume of saline, before the start of surgery. Even though the incidence of post operative pain and PONV were small in both treatment groups, the time to home readiness was significantly shorter in the Dexamethasone group. Besides there was no increase in the incidence of wound infections or hematoma formation in the Dexamethasone group when compared to the saline group. In meta analysis done by Xian Wangetal ${ }^{14}$ comparing effects of Dexamethasone and Ondansetron in
PONV in laparoscopic surgery, Dexamethasone has comaparable effectiveness in preventing PONV with that of Ondansetron within $24 \mathrm{hrs}$ of surgery. In early postoperative period, Ondansetron was better at decreasing PONV than Dexamethasone, while in late period, Dexamethasone was more effective in preventing PONV.

The side effect of Dexamethasone $\mathrm{I} / \mathrm{V}$, transient perineal itching, occurred in $36.7 \%$ patients ,which subsided within a minute was thought to be due to the vehicle of the drug. Side effect of Ondansetron like headache was not significant in the study group. Although no cost benefit ratio could be analysed using the present study, Dexamethasone, with comparable effect as Ondansetron, in the prevention of PONV could be a cheaper alternative.

Our study has a few limitations. Since study does not use a placebo control, the actual efficacy of the two drugs in the prevention of PONV, could not be determined. Since ENT surgeries have a higher incidence PONV than other surgeries, the inclusion of a placebo control group was avoided on ethical grounds. When comparing two or more drugs, it is important to make the comparison between demonstrably equipotent doses. The best way to accomplish this is to establish and compare dose response curves. This is not practical in a study like this and it is possible to argue that the comparison may be inaccurate, as equipotent doses were chosen arbitratory. A dose response curve for Dexamethasone in prevention of PONV has not been prepared to date, in similar studies of the past. The dose of $8 \mathrm{mg}$ is arbitrarily chosen and in comparison with that used in similar studies described earlier. Since data collected from only 30 patients in each group, generalization of results has to be done with caution.

\section{Conclusion}

Our study showed that Ondansetron has a better effect clinically in the prevention of PONV in the early postoperative period when compared to Dexamethasone, though not statistically 
significant. The side effects noted were mainly that of Dexamethasone, but were transient, self limiting and not debilitating to patients. Dexamethasone provides a cheaper alternative to Ondansetron with comparable effect in preventing postoperative nausea and vomiting

\section{References}

1. Watcha, MF, White PF: Post operative nausea and vomiting: its etiology, treatment and prevention. Anaesthesiology 77: 162-184, 1992.

2. Kovac AL: Prevention and treatment of post operative nausea and vomiting. Drugs 59: 213-243, 2000.

3. Brunce, KT and MB Tyres (1992). The role of 5HT in post operative nausea and vomiting. British Journal of Anaesthesia 69 (Supplement!): 60S - 62S.

4. Grunberg S.M, and P.J.Hesketh (1993) Control of chemotherapy induced emesis. New England Journal of Medicine 399: 1790-1796.

5. Allan SG, Leonard RCF: Dexamethasone antiemesis and side effects. Lancet 1986; 1. 1035 .

6. Naylor Ri, mall FC. The physiology and pharmacology of post operative nausea and vomiting. Anaesthesia 49: 25, 1994 (suppl).

7. Kenny GN. Risk factors for post operative nausea and vomiting. Anaesthesia 49: 610, 1994 (Suppl).

8. R.Thomas, N.Jones. Prospective randomized dTible blind comparative study of Dexamethasone, Ondansetron, and Ondansetron plus Dexamethasone as prophylactic antiemetic therapy in patients undergoing day-case gynaecological surgery. British Journal of Anaesthesia. 2001; 87: 588-592.

9. B.Subramaniam, R.Madan, S. Sadhasivam et al. Dexamethasone is a cost effective alternative to Ondansetron in preventing
PONV after paediatric strabismus repair British Journal of Anaesthesia 2001; 86:84-89.

10. Jhi-Jaung Wang, Shung - Tai HV et al. Dexmathasone prophylaxis of nausea and vomiting after epidural morphine for post cesarean analgesia. Canadian Journal of Anesthesia 2001; 48: 185-190.

11. Jhi-Jaung Wang, Shung - Jai Ho et al. The effect of timing Dexamethasone administration on its efficacy as a prophylactic antiemetic for post operative Nausea and vomiting. Anaesthesia and analgesia 2000; 91: 136-139.

12. Khosrou H Naghibi, Hashemi SJ et al. comparison of metoclopramide, Dexamethasone and their combination for prevention of post operative nausea and vomiting in strabismus surgery. Medical Journal of Islamic Academy of Science. 2000 Vol. 13.

13. Margarita, Coloma, Larry. L Duffy et al. Dexamethasone Facilitates discharge after outpatient anorectal surgery. Anaesthesia and Analgesia 2001; 92: 85-88. 